DOI 10.37882/2223-2982.2020.04.08

\title{
ФАКТОРЫ ЗРЕЛИЩНОСТИ ПОКАЗАТЕЛЬНЫХ СПОРТИВНЫХ ВЫСТУПЛЕНИЙ
}

\section{SHOWING FACTORS OF INDICATIVE SPORTS SPEECHES}

D. Vlasov

Summary: The article discusses the synthesis of art and sport in culture. The author analyzes the possibilities of demonstrative sports performances from the standpoint of their entertainment and the specifics of its role. The relevance of the processes of synthesis of art and sports is emphasized by the massive attention to significant sporting events. The role of the synthesis of art and sport is expressed in the translation through them of the main value orientations of culture: aesthetic, national, artistic and expressive (in terms of the physical capabilities of the human body). The significance of demonstration sports is determined by their humanizing potential. This potential is revealed in the processes of personality integration into the system of cultural and aesthetic relationships created on the basis of the synthesis of art and sport in a common culture. Results: the article reveals the main factors of spectacular spectacular sports performances; The main characteristics of factors are determined from the standpoint of enhancing the role of the synthesis of art and sport in culture.

Keywords: indicative sports performances, entertainment, factors, synthesis of art and sports in culture, humanizing potential.
$\mathrm{B}$ ысокий уровень зрелищности спортивных событий в условиях современных социокультурных реалий очевиден. На сегодняшний день уровень и масштаб спортивных мероприятий во многом определяется компонентом зрелищности решений (сценических, декорационных, демонстрационных и пр.) Эти решения характеризуются особой функцией общественных отношений (отношения коммуникации на основе средств культуры, диалог культур) и являются обусловленными выражениями массовой потребности в культуре достижений возможностей человеческого тела и духа [2].

Актуальность разрабатываемой проблематики очевидна. Она связана с видением потенциала спорта в решении глобальных проблем современности. Разработку концепций, которые отражали бы совершенствование социокультурных и ценностно-смысловых ориентаций социума, связывают с возможностями зрелищных показательных выступлений. Недаром даже в ресурсах информационно-справочных систем, используемых в международном формате для систематизации произведений науки, периодики, литературы и т.д., массовые развлечения, спорт и зрелищные искусства имеют единый исходный классификационный код [9].
Власов Денис Владимирович,

аспирант, преподаватель, ГБОУ ВО РК «Крымский университет культуры искусств и туризма» vlasov93@yahoo.com

Аннотация: В статье рассматривается проблематика синтеза искусства и спорта в культуре. Автор анализирует возможности показательных спортивных выступлений с позиций их зрелищности и специфики ее роли. Актуальность процессов синтеза искусства и спорта подчеркивается массовым вниманием к показательным спортивным мероприятиям. Роль синтеза искусства и спорта выражается в трансляции через них основных ценностных установок культуры: эстетических, национальных, художественно-выразительных (с точки зрения физических возможностей тела человека). Значимость показательных спортивных выступлений определяется их гуманизирующим потенциалом. Этот потенциал раскрывается в процессах интеграции личности в систему культурно-эстетических взаимоотношений, создаваемых на основе синтеза искусства и спорта в общей культуре. Результаты: в статье выявлены основные факторы зрелищности показательных спортивных выступлений; определены основные характеристики факторов с позиций усиления роли синтеза искусства и спорта в культуре.

Ключевые слова: показательные спортивные выступления, зрелищность, факторы, синтез искусства и спорта в культуре, гуманизирующий потенциал.

Значение факторов зрелищности показательных спортивных выступлений является очень высоким. Они выполняют специфическую культурно-обменную (определяющую готовность субъекта к восприятию иной национальной концепции культуры как возможности обогащения собственного культурного опыта, а также передаче своего), а также культурно-коммуникативную (признающую уникальность любого культурного опыта в его проявлении при сохранении собственной культурной самоидентификации) функции. Это позволяет формировать особые духовные ценности, определяющие связи с гуманизирующим потенциалом социума.

В связи с вышесказанным, целью статьи стал анализ основных факторов зрелищности спортивных показательных выступлений.

Задачи:

- обосновать значимость формирования нового феномена массовой культуры на основе синтеза искусства и спорта, реализующегося в показательных спортивных выступлениях;

- обосновать значимость расширения культурных функций спортивных показательных мероприя- 
тий, обусловливающих гуманизацию социокультурных отношений в социуме;

- выявить основные факторы зрелищности спортивных показательных выступлений.

Mетоды: теоретического анализа, историко-описательный метод, обобщения.

Новизна:

- возможности информационной эпохи позволяют сегодня с максимальной выгодой для формирования массового сознания и массовой культуры трансформировать положительный эффект организации и проведения зрелищны спортивных и показательных спортивно-массовых мероприятий, для чего необходим анализ потенциала факторов зрелищности;

- усиление роли спорта в расширении спектра международных отношений обусловливает необходимость изучения значимости факторов зрелищности показательных спортивных выступлений: в качестве функции формирования единого мультикультурного пространства; как объекта влияния глобализационных процессов; как эффективного инструмента противодействия негативным последствиям глобализации.

Расширение культурных функций спортивных показательных зрелищ, в границы которых в последнее десятилетие вошли разнообразные проекты («Звезды на льду», «Танцы со звездами» и мн. др.) опосредовали расширяющуюся культурную многоаспектность взаимодействия с обществом. В рамках многих подобных проектов любой желающий человек оказался способным расширить границы своих возможностей, пройти кастинг и поучаствовать в проекте, поучаствовать в соревнованиях. Например, соревнования для взрослых по фигурному катанию открыты для любых возрастов и любого уровня подготовки (чего раньше не было). В шоу могут принять участие отнюдь не только квалифицированные спортсмены или артисты. Во многом это происходит благодаря тому, что доступность спортивных зрелищных выступлений интегрируется в смысло-жизненный ценностный личностный спектр, обусловливающий более эффективное и продуктивное для самой личности приобщение личности к культуре через спорт [4].

Все это говорит о том, что является вполне закономерным рассматривать спорт в тесной связи с культурой и даже в качестве одного из ее значимых компонентов [5].

Спорт, обозначенный Пьером де Кубертеном как повод для искусства, изначально привлекал внимание общественности с позиций «праздничного» смысла жизни. В концепции знаменитого философа Хосе Ортеги-и-
Гассета он обозначался как жизнь второго порядка, т.е. жизнь, подчиненная культурному смыслу существования - смыслу, наделенному особым сущностным значением.

Данное значение с одной стороны, может быть охарактеризовано как кажущаяся (с практической точки зрения) «бесцельность», а, с другой, «изначальная жизненная активность» и «органичная непринужденность». Так характеризуя спортивное зрелище как основу «культуры и цивилизации», Ортега-и-Гассет называет культуру дочерью «не природы, а спорта» $[6 ; 7 ; 8]$.

Творческий характер спортивных зрелищ, красота совершенного действа, раскрывающая суть уникальной природы человеческого ума, тела и их возможностей передаются нам сегодня через спортивные показательные выступления, составляющие своеобразный «абрис» высших форм деятельности.

Нравственно-эстетический облик показательных спортивных мероприятий позволяющий неуклонно расширять представления и знания как о спорте и культуре народов, так и о мире в целом, регулируется императивами красоты, культуросообразного воспитания, информационности и т.п., раскрывающих себя на основе многих факторов, основополагающими из которых являются факторы зрелищности $[1 ; 3]$.

К факторам, определяющим зрелищность показательных спортивных мероприятий (Ермилова, 2015; Кудашов, 2018) справедливо относят:

- спортивное мастерство, художественно-эстетический вкус спортсменов и профессионализм актеров, аккумулирующие художественно-выразительный потенциал спортивного показательного зрелища; данный фактор не только делает показательное спортивное выступление высоко привлекательным в плане выразительных возможностей, но и определяет смысловую глубину выступления, эмоциональную ценность его содержания;

- композицию показательного спортивного выступления, определяющую общее впечатление от насыщенности выступления в масштабах охватываемой площадки, территории и т.п.; данный фактор играет важное значение при восприятии структуры показательного номера, степени насыщенности и выраженности экшена в конкретно взятые временные моменты в рамках распределения смысловой структуры показательного действия и заполненности им пространства; при успешности реализации данного фактора у зрителя возникает впечатление, что в каждый момент времени в каждом «уголке» сцены, площадки и т.п. происходит автономное и, вместе с тем, составляющее 
общую картину действие, наделенное специфическим смыслом: конкретным, но обусловливающим общий план-замысел;

- костюмы и используемый реквизит; роль костюма переоценить достаточно трудно, но, тем не менее, для достижения наивысшего зрелищного эффекта он отвечать определенным требованиям: колористическая решенность, обусловливающая общую гармонию цветового восприятия показательного выступления; использование блестящих, светящихся, переливающихся и пр. элементов, создающих настроение праздника, а также определяющих решение необходимых задач выступления; эстетичность и этичность костюмов, не нарушающая нравственной ценности показательного выступления, а, наоборот, усиливающая данную его сторону; соответствие костюма передаваемой идее выступления и т.д.; функции реквизиты также должны соответствовать достижению общей гармонии и идее показательного номера;

- музыкальное сопровождение, позволяющее достигать особого эффекта на основе гармонии музыки, тональности, эффектов обертонов и т.д.; музыкальное сопровождение усиливает эффект зрелищности выступления, делает его более по- нятным в смысловом восприятии, обеспечивает усиление художественно-эстетической направленности спортивного зрелища;

- художественное оформление, декорации, световые эффекты и т.п.

Считаем необходимым отметить, что каждый из факторов не определяет полностью автономность какоголибо одного из показателей зрелищности. Все факторы достаточно тесно взаимосвязаны и способствуют усилению функций каждого их них. Сочетанием, усилением факторов зрелищности достигается наивысший концепт интеграции, который усиливает зрелищность показательного спортивного выступления. В таких условиях решаются задачи как его участников, так и его реципиентов, что позволяет говорить о развитии особого специфического феномена массовой культуры - художественно-эстетическом, вбирающем в себя уникальность возможностей человека, эстетический идеал и целостный художественный образ. Факторы зрелищности показательных спортивных выступлений являются одними из основных концептов развития спортивной дипломатии, которая в условиях современных реалий играет мощную сближающую роль.

\section{ЛИТЕРАТУРА}

1. Ермилова В.В. Особенности зрелищности в спорте и их трансформация в условиях современного общества // Общество. (реда. Развитие (Теrra Нumana). 2015. № 2 (35). С. 100-103.

2. Козлова В.С. Спорт как социально-зрелищная сфера. Минск: ФУАинформ, 2005. 334с.

3. Кудашов В.Ф., Л.Т. Кудашова, Н.Н. Венгерова. Факторы зрелищности показательных спортивных выступлений // Известия Тульского государственного университета. Физическая культура. Спорт. 2018. № 1. С. 149-156.

4. Ландарь А.А., Носик 0.В., Иванова 0.Л. Мотивация к спорту в нашей жизни // Успехи в химии и химической технологии. 2017. № 14 (195). С. 113-115.

5. Мазуров Ю. Спорт как универсальная культура // Наука в олимпийском спорте. 2014. № 5 (5). URL: http://sportfiction.ru/articles/sport-kak-universalnayakultura/

6. Михайлов В.В. Спорт в мире культуры (по взглядам Х. Ортеги-и-Гассета и Й. Хёйзинга). URL: http://lib.sportedu.ru/GetText.idc?TxtID=682

7. Ортега-и-Гассет Х.0 спортивно-праздничном чувстве жизни / //Философские науки. 1991. № 12. С. 137-152.

8. Сараф М.Я. Спорт и культура (исторический анализ). URL: http://lib.sportedu.ru/GetText.idc?

9. Справочник по УДК. 2015. - URL: http://teacode.com/online/udc/7/7.html

(c) Власов Денис Владимирович (vlasov93@yahoo.com).

Журнал «Современная наука: актуальные проблемы теории и практики» 